\title{
Effect of Pre-Culture Conditions on the Sensitivity of Yeasts to the Glucose Effect
}

\author{
I.A. Amata, P. Germain \\ Department of Animal Science, Delta State University Asaba Campus Delta State Nigeria \\ drifoalexamata@yahoo.com
}

\begin{abstract}
In an experiment to determine the effect of pre-culture conditions on the sensitivity of yeasts to glucose catabolite repression (commonly referred to as the glucose effect), the yeast species Saccharomyces uvarum (carlsbergensis) K19, was used. This species is from the collection of the Industrial Microbiology Laboratory of ENSAIA-INPL, Nancy France. The yeast cells were initially cultured on industrial wort with constant aeration throughout the culture period in the first instance and without aeration throughout the culture period in the second instance, creating aerobic and anaerobic conditions. The yeast cells from the two culture media were harvested and placed in media containing known concentrations of glucose and maltose as substrates and fermentations were carried out at $30^{\circ} \mathrm{C}$. Cells were harvested during exponential growth and the specific rate of fermentation (fermentation intensity) measured using the Warburg respirometer. Irrespective of initial and main culture media used, yeasts from anaerobic pre-culture media had significantly $(P>0.05)$ lower fermentation intensities than those cultivated initially under aerobic conditions. Fermentation intensity of yeast cells on glucose after pre-culture on glucose is significantly $(P<0.05)$ lower for yeast cells grown under anaerobic conditions when compared to cells grown under aerobic conditions. Oxygen limitation during preculture growth of the yeast cells had significant $(P<0.05)$ effect on the glucose effect (catabolite repression) irrespective of carbon source used as substrate.
\end{abstract}

\section{INTRODUCTION}

In nature, carbon and nitrogen sources always occur in diverse and complex forms. Yeast cells are capable of using a wide variety of compounds as carbon and nitrogen sources (Magasanik and Kaiser, 2002). One criterion considered in selecting industrial strains for brewing, baking, wine and the distilling industries is the capability to rapidly and completely utilize the fermentable carbohydrates available (Meneses et al., 2002; Stewart et al., 1998).

When microbes grow in a mixture of different nutrients, they repress the metabolism of the nonpreferred nutrients such as complex carbohydrates until the concentration of preferred nutrients such as glucose are depleted (Aaron et al., 2014). Brewer's wort is a typical example of a nutritional environment containing the sugars sucrose, fructose, glucose, maltose, maltotriose, nitrogen and other non-sugar and non-nitrogenous compounds (Stewart et al., 1998; Boris and Jörg, 2008). In order to select the best options from the diversity of available carbon and nitrogen sources, microbial cells have developed molecular mechanisms of sensing and regulation which include induction and repression of key systems (Hofman-Bang, 1999; Maganaski and Kaiser, 2002; Maganaski, 2005). Saccharomyces cerevisiae and many other types of yeasts may thrive on a variety of carbon sources, but glucose and fructose are the preferred sources. When one of these sugars is present in the culture medium, the enzymes required for the utilization of the alternative carbon sources are synthesized at low rates or are not synthesized at all. Sugar catabolite repression (Gancedo, 1998) ensures an ordered sequence of sugar utilization and during fermentation, brewing strains utilize sucrose, glucose, maltose and maltotriose in this approximate sequence with some degree of overlap (Stewart et al., 1998). However, altered patterns of sugar utilization amongst different strains have been reported (Menese et al., 2002; Beltran, et al., 2004).

Carbon catabolite repression is an important part of global control systems of various bacteria and micro-organisms (Deutscher, 2008). Catabolite repression allows microorganisms to adapt quickly to a rapidly metabolizable and energy source first (Madigan et al., 2009). This is usually achieved through inhibition of the synthesis of certain enzymes involved in catabolism of carbon sources other than the easily metabolizable source. Catabolite repression was first shown to be initiated by glucose 


\section{I.A. Amata \& P. Germain}

and is therefore sometimes referred to as the "glucose effect" (Deutscher, 2008). Yeasts adapted to the fermentation of maltose are sensitive to catabolite repression by glucose (Masschelein, et al., 1963; Daniela, et al., 2001; Beltran et al., 2004; Crépin et al., 2012). Studies on glucose repression in the yeast Saccharomyces cerevisiae reveal a complex regulatory system involving different metabolic pathways (Westergaard et al., 2007).

\section{MATERIALS AND MethodS}

The yeast strain used (Saccharomyces uvarum K19) is from the collection of " Laboratoire de Microbiologie Industrielle de L'ENSAIA, nancy France". Preculture preparations were carried out following the methods described by Amata and Germain (1990), which are modifications of the methods described by Ahvenainen (1982) and by Marc (1982). The method may be described as the progressive fermentation of increasing quantities of wort, the volume of the medium being increased at each step by a factor of 10, until enough yeast in optimal physiological state is produced. The starting volume was $20 \mathrm{ml}$ and the final volume was $2000 \mathrm{ml}$. This procedure is to ensure enough yeast culture for the experiment. Temperature was maintained at $30^{\circ} \mathrm{C}$ throughout this period, using a temperature controlled water bath. For aerobic preculture growth, constant aeration of the medium was carried out, while for the anaerobic growth the process was carried out without aeration. Yeasts from the two preculture media were then added to synthetic media of known concentrations of glucose and maltose.

Fermentations were carried out at $30^{\circ} \mathrm{C}$ using glucose and maltose as the main substrates. The synthetic media had the following composition:

$\begin{array}{lr}\text { Ammonium sulphate }\left[\left(\mathrm{NH}_{4}\right) \mathrm{SO}_{4}\right] & 2.6 \mathrm{gl}^{-1} \\ \text { Potassium dihydrogen phosphate }\left(\mathrm{KH}_{2} \mathrm{PO}_{4}\right) & 1.02 \mathrm{gl}^{-1} \\ \text { Sodium hydrogen phosphate }\left[\mathrm{Na}_{2} \mathrm{HPO}_{4} \cdot 12 \mathrm{H}_{2} \mathrm{O}\right] & 1.23 \mathrm{gl}^{-1} \\ \text { Yeast extracts } & 1.0 \mathrm{gl}^{-1}\end{array}$

The $\mathrm{pH}$ of the synthetic media was adjusted to $\mathrm{pH} 4.5$ and the initial substrate (glucose/maltose) concentrations were adjusted to $8.0 \mathrm{gl}^{-1}$. Cells from the two different preculture media were added to the synthetic media and fermentations carried out at $30^{\circ} \mathrm{C}$ with constant agitation at $250 \mathrm{rpm}$. To ensure uniformity at the time of addition the cellular concentration of the cells was adjusted to $0.65 \mathrm{x}$ $10^{7}$ cells $/ \mathrm{ml}$ using standard turbidimetric techniques relating optical density measurements to dry weight of the cells on a digital colorimeter (Chemtrix type 24). Optical density measurements were carried out at wave lengths of $660 \mathrm{~nm}$. Cells were harvested during the exponential growth phase using an ultra-centrifuge(Beckman LS-508) and washed three times in a buffer solution of calcium chloride $\left(\mathrm{CaCl}_{2} \cdot 5 \mathrm{H}_{2} \mathrm{O}: 1.47 \mathrm{gl}^{-1}\right)$.

The specific rates of fermentation (fermentation intensity) of the harvested cells from the glucose and maltose synthetic media were determined by manometric techniques using the Warburg apparatus (Umbreit et al., 1957).

The reaction medium for manometric measurements had the following composition:

$\begin{array}{lc}\text { Glucose/Maltose } & 20 \mathrm{gl}^{-1} \\ \mathrm{KH}_{2} \mathrm{PO}_{4} & 8.84 \mathrm{gl}^{-1} \\ \mathrm{Na}_{2} \mathrm{HPO}_{4} .12 \mathrm{H}_{2} \mathrm{O} & 0.595 \mathrm{gl}^{-1} \\ \mathrm{CaCl}_{2} .5 \mathrm{H}_{2} \mathrm{O} & 0.417 \mathrm{gl}^{-1}\end{array}$

The cells were harvested from the synthetic medium, centrifuged, then washed three times and then re-dissolved in a calcium chloride $\left(1.47 \mathrm{gl}^{-1}\right)$ buffer solution. The $\mathrm{pH}$ of the medium was adjusted to pH 4.5 using a digital $\mathrm{pH}$ meter. Cellular concentration was adjusted to between $1000-3000 \mu \mathrm{g}$ of wet yeast per $\mathrm{ml}$ as previously described. Each reaction flask contained $2 \mathrm{ml}$ of reactants $(1 \mathrm{ml}$ of reaction medium and $1 \mathrm{ml}$ of yeast cells dissolved in the buffer solution). The trials were conducted at $28^{\circ} \mathrm{C}$ under nitrogen gas (anaerobic conditions). Specific rate of fermentation (fermentation intensity) was expressed as $\mathrm{X} \mathrm{ICO}_{2} \cdot \mathrm{h}^{-1} \cdot \mathrm{mg}^{-1}$ (volume of $\mathrm{CO}_{2}$ produced $/ \mathrm{hr} / \mathrm{mg}$ wet yeast). 
The experiment was a $2 \times 2 \times 2$ factorial experiment with two levels of preculture media (glucose and maltose), two levels of main culture (glucose and maltose) and two levels of oxygen application (aerobic and anaerobic conditions). Data generated were analyzed using the SPSS computer software. Significantly different means were separated using Duncan's multiple range test procedure (Duncan, 1955). Orthogonal contrasts to determine differences between different factor combinations of interest were also carried out.

\section{RESUlTS AND DisCUSSION}

Table 1 shows results for the fermentation intensity of the test materials as affected by oxygen limitation during preculture growth.

Table1. Fermentation intensity as affected by oxygen limitation during preculture growth

\begin{tabular}{|l|l|c|c|}
\hline & & Aerobic preculture growth & Anaerobic preculture growth \\
\hline $\begin{array}{l}\text { Initial growth } \\
\text { on glucose }\end{array}$ & F.I. on glucose & 230 & 120 \\
& F.I. on maltose & 40 & 5 \\
\hline $\begin{array}{l}\text { Initial growth on } \\
\text { maltose }\end{array}$ & F.I. on glucose & 140 & 90 \\
& F.I. on maltose & 240 & 150 \\
\hline
\end{tabular}

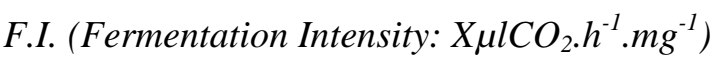

Results show that the fermentation intensity on glucose after initial growth on glucose with yeasts from aerobic preculture growth is $230 \mu 1 \mathrm{CO}_{2} \cdot \mathrm{h}^{-1} \cdot \mathrm{mg}^{-1}$ while fermentation intensity on glucose after initial growth on glucose with yeasts from anaerobic preculture growth is $120 \mu \mathrm{COO}_{2} \cdot \mathrm{h}^{-1} \cdot \mathrm{mg}^{-1}$ and fermentation intensity on maltose after initial growth on glucose is $40 \mu \mathrm{CO}_{2} \cdot \mathrm{h}^{-1} \cdot \mathrm{mg}^{-1}$ for yeasts from aerobic preculture growth and $5 \mu \mathrm{lCO}_{2} \cdot \mathrm{h}^{-1} \cdot \mathrm{mg}^{-1}$ for yeasts from anaerobic preculture growth. Results obtained with maltose as initial substrate show a fermentation intensity of $240 \mu 1 \mathrm{CO}_{2} \cdot \mathrm{h}^{-1} \cdot \mathrm{mg}^{-1}$ for yeasts from aerobic preculture growth and $150 \mu 1 \mathrm{CO}_{2} \mathrm{~h}^{-1} \cdot \mathrm{mg}^{-1}$ for yeasts from anaerobic preculture growth. Fermentation intensity of the test materials on glucose with maltose as the initial substrate is $140 \mu 1 \mathrm{CO}_{2} \cdot \mathrm{h}^{-1} \cdot \mathrm{mg}^{-1}$ for yeasts from aerobic preculture growth and $90 \mu \mathrm{lCO}_{2} \cdot \mathrm{h}^{-1} \cdot \mathrm{mg}^{-1}$ for yeasts from anaerobic preculture growth.

Table 2 below shows the effect of oxygen limitation during preculture growth on percentage decrease in fermentation intensity of the yeast cells. Results show that oxygen limitation during preculture growth and subsequent culture growth on glucose resulted in $47.8 \%$ decrease in fermentation intensity on glucose and $87.5 \%$ decrease in fermentation intensity on maltose. Oxygen limitation during preculture growth and subsequent culture growth on maltose resulted in $35.7 \%$ decrease in fermentation intensity on glucose and $37.5 \%$ decrease in fermentation intensity on maltose.

Table2. Effect of oxygen limitation during preculture growth on percentage decrease in fermentation intensity

\begin{tabular}{|l|l|l|l|l|}
\hline & & Oxygen & $\begin{array}{l}\text { No } \\
\text { oxygen }\end{array}$ & $\begin{array}{l}\text { \% Decrease } \\
\text { in F.I. }\end{array}$ \\
\hline Initial growth on glucose & Fermentation intensity on glucose & 230 & 120 & 47.8 \\
& Fermentation intensity on maltose & 40 & 5 & 87.5 \\
\hline Initial growth on maltose & Fermentation intensity on glucose & 140 & 90 & 35.7 \\
& Fermentation intensity on maltose & 240 & 150 & 37.5 \\
\hline
\end{tabular}

F.I. (Fermentation intensity $\mathrm{X}_{\mu} \mathrm{lCO} \mathrm{O}_{2} \cdot \mathrm{h}^{-1} \cdot \mathrm{mg}^{-1}$ )

Results in Table 3 show the acclimation of the yeast cells to substrate change as affected by oxygen limitation during preculture growth. Under aerobic conditions with glucose as initial substrate, percentage decrease in fermentation intensity is $39.1 \%$ when compared to $25 \%$ under anaerobic conditions. When maltose is used as the initial substrate results show that the decrease in fermentation under aerobic conditions is $83.3 \%$ while under anaerobic conditions it is $96.7 \%$. 


\section{I.A. Amata \& P. Germain}

Table3. Effect of oxygen limitation during preculture growth on acclimation to substrate change

\begin{tabular}{|l|l|l|l|l|}
\hline & & $\begin{array}{l}\text { Native substrate } \\
\text { (F.I.) }\end{array}$ & $\begin{array}{l}\text { Non-native } \\
\text { substrate }\end{array}$ & $\begin{array}{l}\text { \%Decrease } \\
\text { (F.I.) }\end{array}$ \\
\hline Initial growth on glucose & Aerobic conditions & 230 & 140 & 39.1 \\
& Anaerobic conditions & 120 & 90 & 25.0 \\
\hline Initial growth on maltose & Aerobic conditions & 240 & 40 & 83.3 \\
& & & 5 & 96.7 \\
\hline
\end{tabular}

F.I. (Fermentation Intensity $\left.\mathrm{X}_{\mathrm{l}} \mathrm{CO}_{2} \cdot \mathrm{h}^{-1} \cdot \mathrm{mg}^{-1}\right)$

Results in Tables 4 and 5 show the effects of substrate change (catabolite repression) on percentage decrease in fermentation intensity. Catabolite repression is $82.6 \%$ under aerobic conditions with glucose as the culture substrate and $41.7 \%$ with maltose as the culture substrate. Under anaerobic conditions, catabolite repression is $95.8 \%$ with glucose as the culture medium and $40 \%$ with maltose as the culture medium.

Table4. Percentage decrease in fermentation intensity as affected by substrate change (Aerobic metabolism)

\begin{tabular}{|l|l|l|l|}
\hline Substrate & Glucose culture & Maltose culture & $\begin{array}{l}\text { Maltose culture efficiency relative to glucose } \\
\text { culture }\end{array}$ \\
\hline Native & 230 & 240 & $104.3 \%$ \\
\hline Non-native & 40 & 140 & $350 \%$ \\
\hline $\begin{array}{l}\text { Catabolite } \\
\text { repression }\end{array}$ & $82.6 \%$ & $41.7 \%$ & \\
\hline
\end{tabular}

Table5. Percentage decrease in fermentation intensity as affected by substrate change (Anaerobic conditions)

\begin{tabular}{|l|l|l|l|}
\hline Substrate & Glucose culture & Maltose culture & Maltose culture efficiency relative to glucose culture \\
\hline Native & 120 & 150 & $125 \%$ \\
\hline Non-native & 5 & 90 & $1800 \%$ \\
\hline $\begin{array}{l}\text { Catabolite } \\
\text { repression }\end{array}$ & $82.6 \%$ & $41.7 \%$ & \\
\hline
\end{tabular}

Table6. Contrast tests of the various treatment combinations of interest

\begin{tabular}{|l|l|l|l|}
\hline Contrast & Value of Contrast & t-Test value & Significance \\
\hline 1 & 222.20 & 71.906 & $* *$ \\
\hline 2 & 145.00 & 46.924 & $* *$ \\
\hline 3 & 285.20 & 92.294 & $* *$ \\
\hline 4 & 304.40 & 139.31 & $* *$ \\
\hline 5 & -159.40 & -72.95 & $* *$ \\
\hline 6 & -183.60 & -84.03 & $* *$ \\
\hline 7 & 34.80 & 22.53 & $* *$ \\
\hline 8 & 49.60 & 32.10 & $* *$ \\
\hline 9 & 145.60 & 66.64 & $* *$ \\
\hline 10 & 139.60 & 63.89 & $* *$ \\
\hline
\end{tabular}

$* *=$ Highly significant $(P<0.05)$

The treatment combinations are as follows:

1) Glucose as culture vs maltose as culture

2) Glucose as reaction medium vs maltose as reaction medium

3) Aerobic conditions vs anaerobic conditions

4) Glucose as culture and reaction medium vs glucose as culture medium and maltose as reaction medium

5) Maltose as culture medium and glucose as reaction medium vs maltose as culture medium and maltose as reaction medium

6) Maltose as reaction medium vs glucose as reaction medium 
7) Glucose as cultures reaction medium and maltose as reaction medium under aerobic conditions vs glucose as culture medium and maltose as reaction medium under anaerobic conditions

8) Maltose as culture medium and glucose as reaction medium under aerobic conditions vs maltose as culture medium and glucose as reaction medium under anaerobic conditions

9) Glucose as reaction medium under aerobic conditions vs maltose as reaction medium under anaerobic conditions

10) Maltose as culture medium under aerobic conditions vs maltose as culture medium under anaerobic conditions.

Results indicate highly significant $(\mathrm{P}<0.05)$ differences between the treatment combinations of interest.

\section{CONClusion}

Under aerobic conditions maltose culture had significantly $(\mathrm{P}<0.05)$ higher fermentation intensity on its native substrate than glucose on its native substrate and significantly $(\mathrm{P}<0.05)$ higher fermentation intensity on its non-native substrate than glucose on its non-native substrate. Under anaerobic conditions maltose culture had significantly $(\mathrm{P}<0.05)$ higher fermentation intensity on both native and non-native substrates and showed higher catabolite repression by glucose metabolism, $87.5 \%$ when compared to $47.8 \%$. Both glucose and maltose cultures were however significantly $(\mathrm{P}<0.05)$ affected by their non-native substrates under anaerobic conditions. Catabolite repression is much higher when glucose is the culture substrate under aerobic and anaerobic conditions. Under anaerobic conditions the repression is near total $(87.5 \%$ decrease in fermentation intensity). Under aerobic and anaerobic conditions, maltose culture efficiency relative to glucose culture is significantly $(\mathrm{P}<0.05)$ higher. Results indicate significant $(\mathrm{P}<0.05)$ effects of preculture conditions on catabolite repression.

\section{REFERENCES}

Aaron, M.N., Bram, C, Sander, K.G., Gemma, P, Bo Zhu, Boogmans, S., Joao, B.X. and Verstrepen, K.J. (2014). Different levels of catabolite repression optimize growth in stable and variable environments. PLOS Biology 12(1):e1001764. Doi:10.1371/journal.pbio.1001764.

Ahvenainen, J (1982). Lipid composition of aerobically and anaerobically propagated brewer's bottom yeast. Journal Institute of Brewing. 88(1):367-370.

Amata, I.A. and Piere Germain, (1990). The effect of pitching yeast aeration on the production of acetic acid during fermentation with brewer's yeast: an enzymatic approach. Journal Institute of Brewing 96(3); 131-134

Boris, Görke and Jörg, Stülke (2008). Carbon catabolite repression in bacteria: many ways to make the most out of nutrients. Nature Reviews Microbiology 6: 613-624. Doi: 10.1038/nrmicro1932.

Beltran, G., Novo, M., Rozès,N., Mas, A. and Guillamón, J.M (2004). Nitrogen catabolite repression in Saccharomyces cerevisiae during wine fermentation.

Crépin, L., Thibault, N., Sanchez, I., Dequin, S. and Camarasa.,C. (2012). Sequential use of nitrogen compounds by Saccharomyces cerevisiae during wine fermentation: a model based on kinetic and regulation characteristics of Nitrogen permease. Appl. Environmental Microbiology 78(22):8102-8111. Doi:10.1128/AEM.02294-12.

Daniela Š., Zoltán D. and Juraj, ك̌. (2001). Modeling of saccharide utilization in primary beer fermentation with yeasts immobilized in calcium alginate. Applied Biochemistry and Biotechnology .94(2): 147-158.

Deutscher, J. (20080. The mechanism of carbon catabolite repression in bacteria. Current Opinion in Microbiology 11(2):87-93.

Gancedo, J.M. (1998). Yeast carbon catabolite repression. Microbiol. Mol. Biol. Rev. 62(2):334-361.

Hofman-Bang, J. (1999). Nitrogen catabolite repression in Saccharomyces cerevisiae. Molecular Biotechnology 12(1):35-73.

Madigan, M.S., Martinko, J.M., Dunlap, P.V. and Clark, D.P. (2009). Brocks Biology of Microorganisms. $12^{\text {th }}$ ed. San Francisco, CA: Pearson/Benjamin Cummings. 


\section{I.A. Amata \& P. Germain}

Magasanik, B and Kaiser, C.A. (2002). Nitrogen regulation in Saccharomyces cerevisiae, Gene 290(1-2):1-18.

Magasanik, B. (2005). The transduction of the nitrogen regulation signal in Saccharomyces cerevisiae. Proceedings of the National Academy of Sciences, USA, 102 (46):16537-16538.

Marc,I., (1982). Modélisation de la fermentation de la bière dans un réacteur cylindroconique. Thésè de docteur-ingénieur: 68-81.

Masschelein, CH.A. Jenardy, H., Ramos-Juenehomme, C.L. Haboucha, J.E. and Devereux, A. (1963). Characterization biochimique et biophysique de quelques souches de levures brasserie. Proceedings E.B.C: 381-399

Meneses, F.J., Henschke, P.A. and Vladimir, J. (2002). A survey of industrial strains of Saccharomyces cerevisiae reveals numerous altered patterns of maltose and sucrose utilization. Journal Institute of Brewing, 108(3):310-321.

Stewart, G.G. and Russell, I. (1998). Brewing Science and Technology Series 111. The Institute of Brewing London.

Westergaard, S.L., Oliviera, B.C., Olsson, L. and Nielsen J. (2007). A systems biology approach to study glucose repression in the yeast Saccharomyces cerevisiae. Biotech. Bioeng.96 (1): 134145 . 